\title{
Phenomenological Psychology: Husserl's Static and Genetic Methods
}

\author{
Daniel Sousa \\ ISPA-University Institute, Lisbon, Portugal \\ daniel@ispa.pt
}

\begin{abstract}
A new framework for phenomenological psychology is proposed based on Husserl's static and genetic methods. Static phenomenology holds a eidetic psychology centred on the processes of noetic-noematic constitution and elaborates typologies and general notions about human beings in connection with the world. Genetic analysis is research into facticity, it focus on the personal history of a subject, which is constantly in the process of becoming. When the temporal dimension of consciousness is considered, the phenomenological method becomes 'static', as it excludes the factitious dimension of self, its personal and individual history, sedimented in layers of meaning, which are in part pre-reflective, non-thematic and anonymous to the self, but which nevertheless continue to influence the experience of itself with the other and with the world. This paper aims to present some of the fundamental principals of genetic phenomenology and it's application to existential-phenomenological psychotherapy. There are three main aspects underlying genetic-phenomenological analysis as it is being proposed: inner time-consciousness theory, the experiential self and the theory of passive geneses.
\end{abstract}

\section{Keywords}

phenomenological psychology - static - genetic - existential psychotherapy

\section{Introduction}

The aim of this text is to present arguments to support the central claim that phenomenological psychology is an autonomous discipline, with its own 
defined area of intervention. It covers two broad interconnected areas, namely static phenomenology and genetic phenomenology. In modern culture, the terms 'static' and 'genetic' are of course high-charged. However, here they will be used in the sense originally intended by Edmund Husserl.

There are three interconnected points that need to be made about the subject in general:

1. Static phenomenology is an eidetic psychology with its own object of study (i.e. intentional consciousness) and a clearly-defined research method, which includes processes of intersubjective result validation that are duly framed by a particular epistemological approach. It thus has direct bearing on research into classic psychology topics, like perception, memory, language, etc., and as an eidetic psychological science, has as its goal the definition of the invariant structures of human experience and in this sense can be applied to a wide variety of research subjects.

2. Genetic phenomenology, on the other hand, underpins a form of psychology that goes beyond the mere description of the intentional structures of consciousness. This deals with subjects such as pre-reflective and reflective consciousness; the phenomenological notion of self; the creation of identity (the persona), constituted in an intersubjective space; and the analysis of passive geneses and the layers of meaning sedimented in the stream of temporal awareness. The genetic method enables us to plunge into layers of human existence that are pre-reflective, passive and anonymous, though nonetheless active. Genetic phenomenological analysis is research into facticity, as proposed by Husserl. It is the basis of one form of existential phenomenological psychotherapy.

3. Between the static and genetic methods, there is constant dialectic. Constitutive phenomenology based on eidetic dimensions (static phenomenology) enables theoretical bases to be established, which are then explored in more depth and applied using the genetic method. The results achieved by descriptive research can be further explored after being applied at the factical level through the genetic method. This means the genetic investigation may question eidetic dimensions and promote new researches at the descriptive level. Husserl maintained a constant interrelationship between the two methods. Phenomenological psychology aims to do the same. ${ }^{1}$

1 "These are fundamental questions concerning the distinction, but also the ordering of necessary phenomenological investigations. Where they are concerned, I will always speak of static and genetic phenomenology" (Husserl, 2001a, p. 643). 


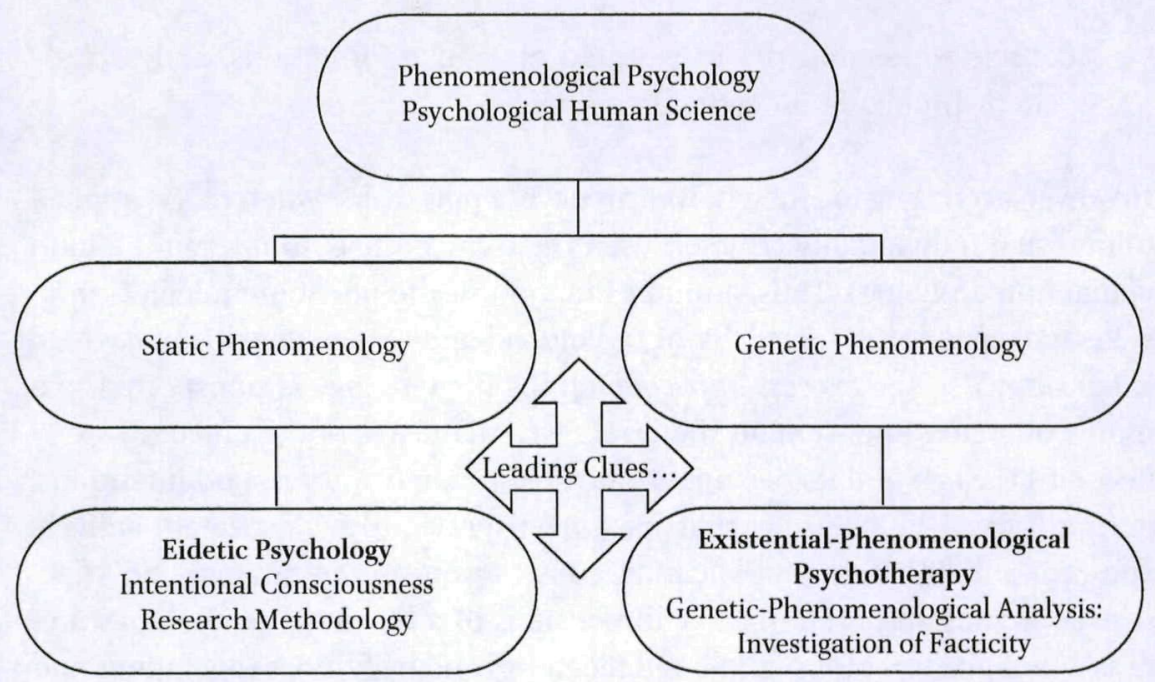

FIGURE 1 Phenomenological Psychology: Static and Genetic Methods.

'Static' phenomenology investigates the processes of noetic-noematic constitution and elaborates typologies and general notions about human beings in connection with the world. ${ }^{2}$ It focuses upon the intentional structures of experience that form part of the human being. The noetic-noematic explorations begun in Logical Investigations focused upon the subjective psychological acts that objectively constitute theories, concepts, judgements, etc., and which are formed as ideal units of meaning. ${ }^{3}$ Static research is more general and abstract in nature and is not concerned with the existential specificity of the self and its individual history.

Now, I can however regard the structures of the stream of lived-experience noetically-noematically in their general typicality; I can (describe) their possible modifications, their interconnections of essence, etc., without pursuing the inquiry into the lawful regularity of the individuality of a monad. The phenomenological-eidetic reduction places me on the footing of a possible monad in general, but precisely not of a monad thought individually and identically, and under the charge of circumscribing the individual identity according to its possibilities and necessities.... I can doubtlessly designate phenomenological investigations as static, investigations that attend to the correlations between constituting

2 (Husserl, 2001a, p. 629).

3 (Husserl, 1977, p. 27). 
consciousness and the constituted objectlike formations, and exclude genetic problems altogether. ${ }^{4}$

However, according to Husserl, we can have 'a new task, ${ }^{5}$ when this is applied to personal individuality (Husserl used the term 'monad' to refer to the individual human being). Thus, another function of the phenomenological project is to consider the specificity of the monad and its personal history, which is constantly in the process of becoming. Phenomenology is transported to a more concrete dimension, to the level of facticity, where the object of study becomes the self and its personal characteristics, motivations and intentions, always limited by horizons that have been previously constituted, actively and passively. ${ }^{6}$ Genetic investigation aims to explore the rational and affective, conscious and pre-reflective dimensions of a historical temporal awareness, influenced by past sedimented meanings and by future expectations and desires. When Husserl comes up against the depth of personal existence, he inflects the ambit of phenomenology.

Finally, we have the phenomenology of monadic individuality, and included in it, the phenomenology of a genesis integral to it, a genesis in which the unity of the monad arises, in which the monad is by becoming.... By the phenomenology of genesis attending to original becoming in the temporal stream, which itself is an originally constituting becoming, and by attending to the so-called "motivations" that functions genetically, a phenomenology of consciousness shows how consciousness arises out of consciousness. ${ }^{7}$

But under the rubric "monad" we have had in mind the unity of its living becoming, of its history, but its also has its living present and it has become in this present, and directly continues in this becoming.... This present has its obscure backgrounds that can be illuminated, in every Now, the present carries its history as the horizon into which it can peer,

4 (Husserl, 2001a, p. 639/640).

5 (Husserl, 2001a, p. 639).

6 'Of particular importance, but noticed very late, is the fact that reflective, so-called 'internal,' experience has very many levels and depth-dimensions and is exceedingly difficult to put into practice whenever one strives to go beyond the most superficial level." (Husserl, 1977, p. 21).

7 (Husserl, 2001a, p. 640/644). 
which it can run through once more and, as it were, can live through once more in the shape of isolated or interrelated rememberings. ${ }^{8}$

The dual dimension of phenomenology is nevertheless unified by a common project. Husserl mentions the notion of the "leading clue" ${ }^{\text {" }}$ to describe the constant dynamic and connection between the static and genetic methods. The two methods are mutually integrative and do not function exclusively in separation. That is to say, descriptive research throws up clues that lead to genetic phenomenology when this is located at the individual level of self. Certain eidetic knowledges, elaborated and typified, about the general structures of experience, may be applied to particular cases. Genetic research, for its part, can also produce clues leading to static phenomenology; by articulating eidetic knowledge at the individual level, it stimulates further questions and new research possibilities.

In a certain way, we can therefore distinguish "explanatory" phenomenology as a phenomenology of regulated genesis, and "descriptive" phenomenology as a phenomenology of possible essential shapes (no matter how they have come to pass) in pure consciousness and their teleological ordering in the realm of possible reason under the headings, "object" and "sense". In my lectures, I did not say "descriptive", but rather "static" phenomenology. ${ }^{10}$

Due to space limitations, this paper has two goals: first, to present a new framework to phenomenological psychology based on Husserl's static and genetic methods as expressed above; secondly, aims to focus on the genetic method and its application to psychology and psychotherapy. This means that the eidetic psychology, which is based upon static phenomenology, will not be considered in this work. Suffice it to say that the static method is characterised by its attempt to describe the way in which objects are manifested to consciousness and to elaborate essential structures of experience which are expressed in eidetic dimensions, general and typified. In short, eidetic psychology has as its object of study the intentional consciousness; its method consider five dimensions (the époche, the psychological phenomenological reduction; the eidetic analysis and intersubjective modes of validating results). The aims of eidetic phenomenological psychology are to shed light to on the intentional

\footnotetext{
8 (Husserl, 2001a, p. 637).

9 (Husserl, 2001a, p. 633).

10 (Husserl, 2001a, p. 629).
} 
phenomena and on the meaning of human experience and the kind of outcomes it can achieve are syntheses of meanings and eidetic results (invariant structures of experience). Moreover, the section about genetic method is highly theoretical, clarifying notions and trying to make explicitly the foundational underpinnings of the genetic-phenomenological analysis.

\section{Genetic Phenomenological Analysis: The Investigation of Facticity}

The genetic method is directly connected to inner time-consciousness theory, which Husserl began working on in 1893 and first demonstrated in his 1905 lectures. These lectures did not yet have a genetic nature, but they ultimately proved to be the point of transition. Husserl himself considered this work to be still formal and abstract, and it would have remained so if time consciousness theory had not been linked to the specific existential nature of self. ${ }^{11}$ However, he continued to work on time consciousness for various years, right into the 1930s, and many of the resulting manuscripts are still unpublished. The crucial question is as follows: when the temporal dimension of consciousness is considered, the phenomenological method becomes 'static', as it excludes the factitious dimension of self, its personal and individual history, sedimented in layers of meaning, which are in part pre-reflective, non-thematic and anonymous to the self, but which nevertheless continue to influence the experience of itself with the other and with the world. For Husserl, the self is never static, absolute and defined, but is rather situated in a living present. This means that the self extends uninterruptedly beyond the present moment, influenced by its past history and conditioned by its expectations (explicit or implicit) of the future. Intentional consciousness never exists only in the present moment; it inhabits the paradox which experiences its existence through a temporal flux which is simultaneously a being-here, a being-no-longer-here and a being-not-yet-there. ${ }^{12}$

In Ideas II, Husserl uses the terms 'monad' and 'person'13 in relation to this facticity, a process of becoming, which constitutes time and is constituted in time, the centre of a surrounding world. Person and world are inseparably inter-

\footnotetext{
11 (Husserl, 2001a, p. 174; Donohoe, 2004, p. 38; Steinbock, 1995, p. 40).

12 "While the static-based relation is of the order of validity, the genetic-based order is a temporal order of motivation. Genetic phenomenology is concerned with becoming in the temporal stream and with the motivations that operate in that flux." (Montavont, 1999, p. 38, my translation).

13 (Husserl, 1989, p. 290).
} 
related. That surrounding world is not only a world in itself but also 'a world for me'. In this work, in distinguishing the natural world from the personal world, Husserl holds that relationships of intentional motivations, distinct from relationships of causality, are present in the history of each person, in their relationship between the Self and the Other. The horizon is not only the analysis of subjectivity, but above all, of intersubjectivity. The person is constituted, develops, knows himself and recognises himself through the intersubjective space. The constitution of the world, the unveiling of self and the establishment of intersubjectivity are inter-dependent and simultaneous processes.

The notion of motivational networks that inhabit the self will imply an approach to Husserl's theory of passive geneses. We will be led by a phenomenology of association that will elaborate on the geneses of meanings created and established throughout the life of the self, in part without its active participation, but which nevertheless influence the possibilities of its experiential horizon. Husserl's phenomenology of association also involves themes of memory, motivational forces, the influence of affectivity and emotion, and that which is known as the zero horizon or zero consciousness. As we shall see, the genetic method plumbs the depths of facticity of existence, assuming that the self has a cluster of abilities and characteristics, habits sedimented throughout its experiential process, which are not immediately accessible but which passively influence the person's action. Each noema has a deep temporally-constituted dimension which only the genetic method can explore. ${ }^{14}$ While the static method is centred upon the noetic-noematic correlation, the genetic method investigates the genesis of meaning present in any intentional unit. The whole of lived experience points towards a temporally- and historically-constituted meaning. Following a "principle of genetic order,"15 it attempts to uncover the genesis of meaning of intentional motivations, both pre-predicative and those elaborated by reason. The process of genetic phenomenological analysis will in part be a distillation of the sedimented layers of meaning that intersubjectively constitute the subject's personality and his experiential horizons. From that interrelational context from which human existence derives, there may emerge conflicts, existential tensions and traumatic processes, for their part sedimented in dissociative processes that operate at the pre-reflective level. ${ }^{16}$ Existential psychotherapy's work of clarification focuses upon the anguish and dissociative processes that form part of the being-in-the-world. ${ }^{17}$

\footnotetext{
14 (Donohoe, 2004, p. 38).

15 (Husserl, 1969, p. 208).

16 (Spinelli, 1997, p. 96; Stolorow, 2007, p. 11).

17 (Spinelli, 1997, p. 6).
} 
There are three main aspects to the rationale underlying genetic-phenomenological analysis and its application to phenomenological psychology as it is being proposed: inner time-consciousness theory, the experiential self and the theory of passive geneses. This theoretical structure will be framed by the method of genetic phenomenological analysis, which will in term be complemented by other concepts.

\section{Inner Time-Consciousness Theory}

\section{The Dynamic Structure of Temporal Consciousness}

Husserl considered inner time-consciousness theory to be the cornerstone of the theoretical edifice of phenomenology. ${ }^{18}$ It reflects and expresses the fundamental aim of the phenomenological project: to understand how subjectivity can manifest itself, how it is a constituent of beings in the world and how it is constituted to itself. Husserl wondered how consciousness perceives an object with temporal extension, such as a melody, but also asked how consciousness is manifested to itself. ${ }^{19}$ According to him, it would be impossible to perceive objects with temporal extension if consciousness could only apprehend the "now" moment of the object and if the stream of consciousness were no more than the sum of a series of unconnected "nows". ${ }^{20}$ To explain the apprehension of temporal objects, and situations involving changes and successions, three technical terms are used: primordial impression, retention and protention.

Let us consider a sequence of three sounds making up a melody. When the first sound is heard (the now moment of the object), the primordial impression is activated. This never occurs in isolation, as that would not enable the object's temporality to be perceived; thus, it is always accompanied by a retention (i.e. of the moment-just-passed), which allows access to the moment it dives into the past. Simultaneously, protention is a more-or-less undefined form that intuits the moment that is about to happen. Consciousness perceives temporal objects "in blocs", in a three-part dynamic temporal structure in which the temporal phases (past, present and future) of the object are presentified "together" in a concentrated form. Thus, in inner time consciousness, retention and protention are not past or future in relation to the primordial impression but presented together with it. Retention and protention should, however, be distinguished from thematic recollection and expectation. The former are

\footnotetext{
18 (Husserl, 1977, p. 154; Zahavi, 2003, p. 165; Held, 2003, p. 43).

19 (Husserl, 1994, p. 56).

20 (Zahavi, 1999, p. 63).
} 
passive activities that occur without any intentional action on the part of the subject; that is to say, there is no active contribution from the consciousness. Thematic recollection and expectation, on the other hand, are independent intentional acts that depend at least in part upon the subject's actions, i.e. they are voluntary. ${ }^{21}$

The primordial impression-retention - protention structure is constantly being updated and altered in the stream of consciousness. Each new retention is always retention of the previous primordial impression and of the primordial impression that preceded that. As time passes, objects and the experience of them lose qualities and definition. Retentions gradually weaken until they eventually become imperceptible. ${ }^{22}$ The crucial question from the psychological point of view is that the example of sound may be extended to any kind of experience lived in the first-person perspective. What is given in the self in "living flesh" ${ }^{23}$ undergoes a transformation during the continuous retentional process in the stream of consciousness. It is successively relegated to the past, so that the continuous emergence of new primordial impressions occurs inseparably from a retentional transformation.

\section{Manifestation of Subjectivity and Temporality}

For Husserl, inner time consciousness theory had a much more important aim than merely explaining the perception of temporal objects. It had to do with the very manifestation of subjectivity. ${ }^{24}$ Therefore it is important to mention the concept of double intentionality: transversal intentionality (Querintentionalität) and longitudinal intentionality (Längsintentionalität). ${ }^{25}$ Let us go back to the example of the melody. When we hear a sound, an intentional act occurs, enabling an intentional object, different from consciousness, to manifest itself. The act is intentional because it allows the manifestation of something different from itself, but at the same time the act is also manifested to itself. This is therefore a double intentionality, in which the object is given by means of the act which, as well as manifesting the intentional object, also manifests itself.

"We should, then, gain nothing by transferring into ourselves the time that belongs to things, if we repeated 'in consciousness' the mistake of defining it as a succession of instances of nows. Yet this is what psychologists do when they try to 'explain' consciousness of the past in terms of memories, and consciousness of the future in terms of the projection of those memories ahead of us" (Merleau-Ponty, 2002, p. 479).

22 (Husserl, 1994, p. 63; Zahavi, 2005, p. 57/58; Zahavi, 1999, p. 66; Bernet, Kern \& Marbach, 1993, p. 103).

23 (Husserl, 2001, p. 217).

24 (Zahavi, 1999, p. 67).

25 (Husserl, 1994, p. 107). 
From the last explanations, we can give the following response: there is a single unique flow of consciousness which constitutes the temporal unity immanent in the sound, and at the same time, the very unity of the flow of consciousness. ${ }^{26}$

There are two intentionalities that are inseparably united and intertwined, effectively two sides of the same coin. The intentional act and the stream of consciousness are integral inseparable parts. ${ }^{27}$ Each retention implies a double intentionality. The intentional act is called the transversal intentionality of retention. The intentionality of retentions (that is, the flow of consciousness itself) is called longitudinal intentionality. This is not a supplementary retention that is added to the retention of sounds. If it were, this would imply infinite regression. The flow is crossed by a longitudinal intentionality that is constantly in unity of coincidence with itself. ${ }^{28}$ As well as being intentional and making possible the manifestation of something different from itself (the intentional object), the act is characterised by an "inner consciousness", in the sense that it is manifested to itself. ${ }^{29}$

Consequently, the flow is crossed by a longitudinal intentionality which, in the course of the flow, is constantly in a unity of coincidence with itself. $^{30}$

For Zahavi, one of the crucial questions arising from a correct interpretation of double intentionality is that inner time-consciousness is the pre-reflective consciousness of acts of consciousness and lived experiences. ${ }^{31}$ As Sartre also mentioned, inner time-consciousness theory is the most appropriate place for understanding Husserl's explanation of the pre-reflective structure of consciousness. ${ }^{32}$ The stream of temporal awareness is the name given to a pre-reflective consciousness, which is not an intentional act, an internal object or temporal unity, but rather a basic permanent dimension of human consciousness. ${ }^{33}$ Experiences become the object for consciousness only when

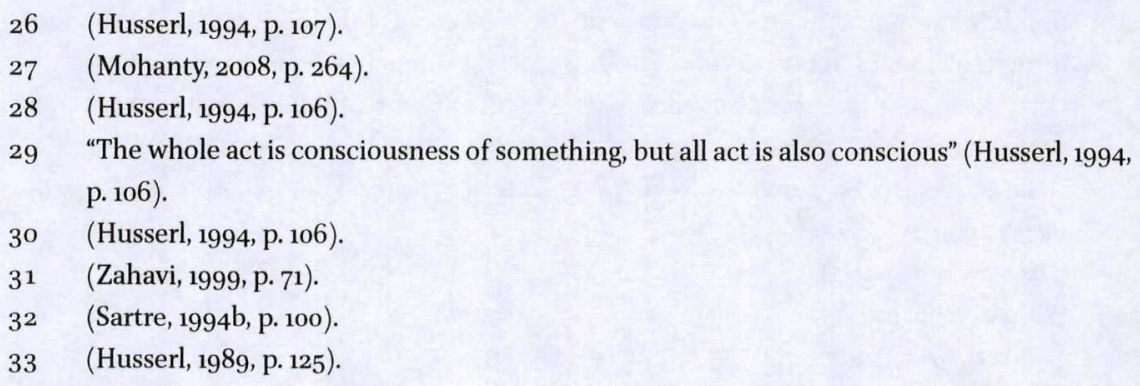


reflexivity is introduced; for Husserl, the object is at this point transcendental in relation to consciousness, i.e., there exists a difference between the object and intentional consciousness. The flux of consciousness and intentional acts are not two distinct flows but two different ways of manifesting a single stream.

\section{Pre-Reflective Consciousness and Temporal Identity}

It is important to remember that retentional pre-reflective consciousness is a modification, in the sense that, when the primordial impression becomes retention, we are not only before the object as it was given (for example, the melody), but as it was experienced.$^{34}$ Effectively, the stream of consciousness of retentions and protentions form a chain of experiences that transcend natural givens; they are not experienced neutrally in their crude form. ${ }^{35}$ Therefore, Husserl's theory demonstrates how all experience is constituted in temporal awareness, a consciousness that is not thematic and which is the province of a non-objectified self. Every experience is retained in the stream of consciousness, even when it is not constituted as a reflective object or instituted in objective time, forming a backdrop that constitutes the experiential horizon. Longitudinal intentionality anchors subjectivity, as Merleau-Ponty pointed out; retentions and protentions are intentionalities that fasten subjectivity to its surroundings. ${ }^{36}$ Through time awareness, the pre-objectified self is continuously and uninterruptedly lived in a multiplicity of experiences that are constantly being updated in the retentional chain, while it nevertheless recognises itself pre-reflectively as the same over time, despite the changes.

Consciousness is a stream of lived experiences, in other words, a flowing manifold. But these many different types of lived experiences are all known to me as "my experiences". Through their all belonging to "me", these experiences all belong together, and thus they form a unity. This synthetic unity of the diversity of the stream of lived experiences is, according to Husserl, temporality. ${ }^{37}$

In this sense, inner-time consciousness is the primordial space for the constitution of identity. There is unity, a flow of consciousness, a self, a personality. 38

34 (Zahavi, 2003a, p. 172).

35 (Rodemeyer, 2003, p. 140).

36 (Merleau-Ponty, 1945, p. 476).

37 (Held, 2003, p. 43).

$3^{8}$ "The pure Ego is to emphasize it expressly, numerically one and unique with respect to 'its' stream of consciousness. If it posits in its cogito, in its experiences, a man, and in him 
Husserl's concept of inner time-consciousness is a theory about the notion of a basic identity established in time, where the lived present is an opening, a present in depth, ek-static, which enables the experiences of subjectivity and the constitution of selfhood to be scrutinized. Time consciousness is the basis of selfhood, meaning and reason. ${ }^{39}$ The temporality of consciousness enables the experiential world of subjectivity to be analysed.

If time is the thread with which the personal narrative is woven, it is understandable that the dynamic structure of temporal awareness is affected by the presence of existential tensions and psychological disturbances. Stolorow and his colleagues imported phenomenology to psychoanalysis and, over the course of several decades, developed the notion of "dynamic intersubjective fields", which presupposes a focus on affectivity in human experience and considers it to be both regulated and compromised by relational systems. ${ }^{40}$ This idea was always central in existential psychotherapy, which "assumes that all reflections uponourlivedexperiencereveal thatexistence is relationally-derived."41 What Stolorow means is that the presence of emotional trauma in the human experience seriously compromises the $e k$-static unity of temporal existence. ${ }^{42}$ Traumatic experience causes the temporal awareness of the past to congeal in the present, so that one remains captive there or returns constantly to it, while the future loses significance. ${ }^{43}$ The line of flux of temporal awareness collapses, which means that clinical dissociation may be understood in terms of a disorganization of personal meaning sustained by temporality. ${ }^{44}$ The dynamic structure of temporal awareness will necessarily have to be considered from the therapeutic perspective when there are dissociative processes arising out of existential tensions and conflicts.

\section{Experiential Selfhood}

While recognising that it is reductive to work with only one notion of self (the term is multi-faceted), Zahavi, basing himself on classical names from

a human personality, then it posits implicitly, as pertaining to him, a pure Ego with its stream of consciousness" (Husserl, 1989, p. 117).

39 (Merleau-Ponty, 1945, p. 487).

40 (Stolorow, 2007, p. 1).

41 (Spinelli, 1997, p. 96).

42 (Stolorow, 2007, p. 20).

43 (Stolorow, 2007, p. 20).

44 (Stolorow, 2007, p. 20). 
phenomenology such as Husserl, Heidegger, Sartre and Merleau-Ponty, suggests that there is an 'experiential dimension of selfhood.'45 This is a basic form of selfhood, a core self (the 'experiential self') which precedes and underpins the narrative self (or, if we prefer, the constitution of personal identity). The fundamental question of the phenomenological theory of pre-reflective consciousness is that, in an experiential dimension, all and any experience in a firstperson perspective immediately implies a basic awareness of self. ${ }^{46}$ In order to gain access to a core self, it is necessary to investigate experiences lived in the first person. For example, when I perceive an object, experience an emotion, recall a past event or bring forth a thought, I simultaneously have a basic prereflective awareness of myself. To be self-aware is to have first-person experiences that are characterised by the quality of being mine. The basic dimension of human existence and the constitution of self does not take place in opposition to the stream of consciousness or separately from it; on the contrary, the core self is submerged in the experiential world, i.e. in the experiential flow of temporal awareness. Thus, self-understanding implies an investigation into the experiential interaction between the self and the world, which is clearly the main aim of existential psychotherapy. The experiential self is the conceptual articulation of the being-in-the-world.

It is possible to identify this pre-reflective sense of mineness with a minimal, or core, sense of self... In other words, the idea is to link an experiential sense of self to the particular first-person givenness that characterizes our experiential life; it is the first-personal givenness that constitutes the mineness or ipseity of experience. One advantage of this view is that, incidentally, it makes clear that self-awareness is not to be understood as an awareness of an isolated, worldless self, nor is the self located and hidden in the head. To be self-aware is not to interrupt the experiential interactions with the world in order to turn the gaze inward; on the contrary, self awareness is always the self-awareness of a worldimmersed self. The self is present to itself to precisely and indeed only when worldly engaged.... The phenomenological notion of an experiential self is fully compatible with a strong emphasis on the fundamental intentionality, or being-in-the-world, of subjectivity. ${ }^{47}$

\footnotetext{
45 (Zahavi, 2007, p. 187; Zahavi, 2005, p. 115).

46 (Husserl, 1994, p. 105; Heidegger, 1982, p. 159; Sartre, 1994b, p. 100; Merleau-Ponty, 1945, p. 487).

47 (Zahavi, 2005, p. 125/126).
} 
As Sartre points out, if I feel pleasure, I am aware of feeling pleasure; the experience of pleasure does not exist first, to which the awareness of feeling pleasure is later added. Pleasure is awareness of feeling pleasure. The way of being of subjectivity is to be aware. ${ }^{48}$ "For the law of being in the knowing subject is to-be-conscious. ${ }^{49}$ Perceiving a table is not a matter of affirming that the table exists in itself, but that it exists for $m e^{50}$ The awareness of an object is simultaneously a pre-reflective consciousness, a non-positional consciousness. ${ }^{51}$ For Sartre, this basic selfhood does not yet mean self-awareness. It is necessary to distinguish between pre-reflective consciousness, and reflective consciousness, which is now self-knowledge. ${ }^{52}$ We will see below that, for Husserl, intersubjectivity is constitutional; but here what matters is the fact that any experience lived in the first person is totally exclusive and unique.

But this unique distinctive character is clear, consisting in this, that an all-inclusive synthesis pervades the streaming of lived experiences and all existence synthetically constituted in them as persisting, an all inclusive synthesis by means of which even unreflectedly I am constantly a pole of identity in relation to which everything else is 'objective'.53

Merleau-Ponty also indicated that through temporality there arises selfhood; that is to say, consciousness always maintains a relationship of itself for itself. ${ }^{54}$ If there are qualitative differences in the way experiences are lived, there is a quality that remains unaltered - the fact that the experiences are mine..$^{55}$ Along similar lines, Heidegger understands that the essence of Dasein lies in the existence that is characterised by a being of mine. The Dasein is unveiled in

48 (Sartre, 1994b, p. 102).

49 Translation p. xxvii. "Car la loi d'être du sujet connaissant, c'est d'être-conscient" (Sartre, 1943, p. 17).

50 "That is of course not sufficient to permit me to affirm that this table exists in itself-but rather that it exists for me." (Sartre, 1969, p. xxviii).

51 (Sartre, 1943, p. 18/19).

52 "Thus reflection has no kind of primacy over the consciousness reflected-on. It is not reflection which reveals the consciousness reflected-on to itself. Quite the contrary, it is the non-reflective consciousness which renders the reflection possible...." (Sartre, 1969, p. xxix).

53 (Husserl, 1977, p. 208).

54 (Merleau-Ponty, 1945, p. 487).

55 "As something selfsame in manifold otherness, it has the character of the Self" (Heidegger, 1962, p. 150). 
and through facticity, a being thrown into the world, with a pre-comprehension and an intrinsic connection to himself, prior to any interpretative movement.

We are ourselves the entities to be analysed. The Being of any such entity is in each case mine. Because Dasein has in each case mineness (Jemeinigkeit), one must always use a personal pronoun when one address it: "I am", "you are". Furthermore, in each case Dasein is mine to be in one way or another. ${ }^{56}$

\section{Experiential Self - 'Streaming' and 'Standing'}

Experiences lived in the first-person perspective are in inner time consciousness in a non-thematic position, submerged in a horizon of potential and possibilities. ${ }^{57}$ The self of inner time consciousness is primordial and originary, as it slips through the retentional time chain of consciousness, although remaining constantly self-aware. At a deep dimension of self, streaming and standing are one and the same inner time consciousness. ${ }^{58}$ This gives rise to the paradox of the person that knows himself and recognises himself as the same subjectivity over time, but who simultaneously identifies with a multiplicity of different experiences, and who is in constant change. ${ }^{59}$ This is what Husserl called the 'living present'.60 Although the self lives constantly in a chain of experiences that go on throughout life, and cannot be identified outside that flow, the self given in the first-person perspective is at the same time an invariant dimension that is maintained throughout the multiplicity of experiences. ${ }^{61}$

Through this pre-objective self-identification, my primordial ego, on the one hand is something unchanging, that is, it is standing and remaining; on the other hand, through this pre-objective self-distancing, it is something living and streaming, that is, something that can become something different in comparison to what it was before. Thus my ego, in its deepest dimension, is a living being, wherein "standing" and "streaming" are one. ${ }^{62}$

\footnotetext{
56 (Heidegger, 1962, p. 67).

57 (Held, 2003, p. 44).

$5^{8}$ (Held, 2003, p. 47).

59 "The unity of immanence is the unity of a constant flux, in the nexus of which all immanent duration and change are constituted." (Husserl, 1989, p. 127).

6o (Husserl, 2003, p. 256).

61 (Zahavi, 2005, p. 132).

62 (Held, 2003, p. 47).
} 
At this level, it is not a matter of the subject's transparency to himself, or of a reflective process of construction of self-knowledge. ${ }^{63}$ The crucial aspect is the direct connection between the phenomena experienced and the firstperson perspective, in which there already exists a primordial non-thematic pre-objective dimension of self. Nothing can be present to the self if it is not self-aware. The experiential self may constitute itself as a person, construct its personal identity through language and narrative processes - above all, as we shall see, through the intersubjective space and relational networks-but the experiential self is a base structure of consciousness that precedes any narrative dimension. ${ }^{64}$

From the psychological point of view, what is important is that the experiential self cannot be understood or considered independently of its connection with the world. The self is, in first place, present in the experiential life, intrinsically connected to the other and to the world. The experiential self, as it is defined by phenomenologists, is similarly conceptualised in existentialphenomenological psychotherapy, which considers an irreducible grounding of relatedness ${ }^{65}$ as the first principle of self:

Phenomenologically influenced perspectives on the self begin by asserting its indissoluble and indivisible interrelational grounding. Nothing meaningful can be stated or experienced about 'self' without an implicit reliance upon the self's interrelational placement in the world. ${ }^{66}$

Research into phenomenological psychology and existential psychotherapy is centred on the interrelational dimension, for it is here that the formation and development of self takes place, as well as (in the presence of interpersonal blockages) psychological disturbances.

\section{Phenomenology of Passivity: The Depths of Facticity}

Following Husserl, it is possible to go one step deeper to understand the meaning that is present in the background of lived experiences, which always contains a dimension that is veiled and obscure. Later, it will be important to distinguish the notion of self from the concept of person (monad), a distinc-

\footnotetext{
63 (Zahavi, 2003a, p. 160).

64 (Zahavi, 2007, p. 191).

65 (Spinelli, 2007, p. 12).

66 (Spinelli, 2001, p. 41).
} 
tion that leads to an explanation of the intersubjective constitution of personal identity, thus enabling closer connections to be made with psychology and with psychotherapy. However, for Husserl, there are also intrinsic motivations belonging to each subject, which are veiled, hidden, and are not immediately accessible. These are what Husserl considered to be a backdrop of experiences that the self does not immediately understand, but which nevertheless continue to "knock on the door of consciousness." 67

These are geneses of meaning that have been established passively, without the participation of the active self, and which have gradually formed sedimentations and habits that become part of the subject's history and influence his experience. Research using the genetic method acquires pertinence when the aim is to understand not only the active self but to deal with the depth of passive experience that involves the development of the person, and his present and future expectations. The genetic method thus makes vertical connections between the basic self and a personal identity, and between progressive and regressive movements of intentional motivations. It also deals with multiple associations that occur in passive geneses in the dynamic structure of temporal consciousness, where the active self is not the main actor but nevertheless has an influence.

But then genetic investigation is also necessary, the exploration of the geneses, passive as well active, in which the monad develops and evolves, in which, within the monad, the monadic I acquires its personal unity and becomes a subject of a surrounding world, which is partly given to it passively in advance, partly actively shaped by itself, and then at highest level becomes the subject of a history.

Our starting-point was inner time consciousness theory; however, this on its own may be formal and abstract, as Husserl himself pointed out, ${ }^{68}$ if it is not directly related to the contents of facticity and the existential dimension of subjectivity that is always imbued with personal characteristics, memory and affectivity. It is in that connection, it is argued, that inner time-consciousness

\footnotetext{
67 (Husserl, 1989, p. 105).

68 "Time-consciousness is the primordial place of the constitution of the unity of identity or of an objectlike formation, of all objectlike formations being given to consciousness, then we are still only talking about that consciousness which produces a general form. Mere form is admittedly an abstraction and thus from the very beginning the analysis of the intentionality of time-consciousness and its accomplishment is an analysis that works on [the level of] abstractions." (Husserl, 2001a, p. 173).
} 
theory and passive geneses allow phenomenology to go beyond the descriptive mode to elaborate a theory of change and personal development, a theory which is concerned above all with the constitution of a personality or personal identity that can be applied to psychology and psychotherapy. See, for example, the lectures on phenomenological psychology that he gave in Freiburg in 1925, in which he refers to passive geneses as an integral part of the constitutions of personality, to the necessary connection between time consciousness and facticity, and how the collapse of certain personal assumptions may bring about radical changes in the subject:

As regards the psychic life of the lower passive levels, it is everywhere the presupposition for personality." ${ }^{\prime 69}$... Let us bear in mind that every psychic is the unity of a streaming psychic life, and what streams in it as psychic state or act is subordinate to fully unique principles of this stream-unity... However, the psyche is not just streaming life, but a life in which, inevitably, distinctive new unities, habitualities are constituted, that is, the passive and active abilities, abilities of perception, abilities of feeling, abilities of memory, intellectual abilities etc. With these constantly variable abilities we are already referred to the properly essential unity belonging to every psyche, the unity of an identical I as substratum for ability-characteristics pertaining specifically to an I, for personal characteristics which are variable and in fact never resting, and which eventually, in a collapse, can change totally; among them are the strictly so-called character traits; the unity of mental individuality which persists even through character changes, permeates all that. ${ }^{70}$

There remains a question that Husserl perhaps did not respond to and which is of particular interest to psychologists and psychotherapists. This is the question of why the self should collapse. However, by connecting time consciousness with passive geneses and with the notion that existence is intersubjectively derived, it is possible not only to arrive at a theory of development and personal identity, but also to explain the existential conflicts inherent in human experience. This will be demonstrated below.

\section{Active and Passive Self}

Already in Ideas II, Husserl refers to the free self that decides and acts, but mentions that this active self is only one dimension of existence; a great deal of

69 (Husserl, 1977, p. 100).

70 (Husserl, 1977, p. 107). 
personal experience involves a passive self. Even when the self is active, part of it is only passively active. Husserl clearly states at various points in his oeuvre that, even in a hidden dimension, the self is not a nothing. ${ }^{71}$ Investigating the geneses of meaning throughout the process of personal development implies considering the way the self is in constant contact with what Husserl calls hyle 72 $^{2}$ (i.e. all the sensorial givens of experience, such as 'instincts', sensations like pleasure or pain, various types of feelings, wellbeing and illness, all of which form part of the passive dimension of the experience of self and influences it, even before being thematized). ${ }^{73}$

When dealing with the relationship between the experiential self and the constitution of a personal identity, it will be seen that the self is the startingpoint for personal growth; despite always involving a passive dimension, it nevertheless exerts "self-preservation", ${ }^{74}$ and therefore does not cease to be an active agent. The self exerts functions, develops particular competences and has intrinsic motivations; in short, it is the centre of the faculties. ${ }^{75}$ For Husserl, this is only one dimension of self-that of practical reason. ${ }^{76}$ However, even rational dispositions are influenced by passive moods. ${ }^{77}$ Thus, it is important to highlight a crucial point: the self is constantly and simultaneously active and passive; the sediments of ways of being and habits acquired are intertwined with the free will of subjectivity. ${ }^{78}$

Therefore we find, as the originally and specifically subjective, the Ego in the proper sense, the Ego of "freedom," the attending, considering, comparing, distinguishing, judging, valuing, attracted, repulsed, inclines, disinclined, desiring, and willing Ego: the ego that in any sense is "active" and takes a position. This however, is only one side. Opposed to the active Ego stands the passive, and the Ego is always passive at the same time whenever it is active, in the sense of being affected as well as being receptive, which of course does not exclude the possibility of its being sheer

71 (Husserl, 1977, p. 155; Husserl, 1989, p. 106).

72 "Husserl calls such a genesis of egoic subjectivity a hyletic (or material) genesis. Hyle is synonymous with passive, associative, affective, driven and habitual, and is frequently defined as das Ichfremde, namely what is foreign to the I but deeply inhabits me: in short, the alien within myself and inherent in me. (Depraz, 2001, p. 171).

73 (Husserl, 1989, p. 160).

74 (Husserl, 1989, p. 265).

75 (Husserl, 1989, p. 265).

76 (Husserl, 2001b, p. 102).

77 (Husserl, 1989, p. 233; Husserl, 1969, p. 207).

78 (Husserl, 1989, p. 267). 
passivity ..${ }^{79}$ In original genesis, the personal Ego is constituted not only as a person determined by drives, from the very outset and incessantly driven by original "instincts" and passively submitting to them, but also as a higher, autonomous, freely acting Ego, in particular one guided by rational motives, and no tone that is merely dragged along and unfree.... Here habit and free motivation intertwine. ${ }^{80}$

Following the notions of the active and passive self, three central aspects may be identified with regard to Husserl's notion of passive geneses: there are active geneses that occur with the participation of the self and in rational cognitive acts; there is a dimension of passive geneses that promote a mutual influence between the active and passive selves, forming a bridge between passive and active geneses; finally, there is a dimension that is totally passive, in which associative networks of meaning creation occur without the active participation of the self. ${ }^{81}$ The space of pure passivity is that of "primordial constitution", because this occurs prior to a rational and thematic constitution on the part of the subject.

\section{Passive "Unconscious" Geneses}

If we accompany Husserl in his elaboration of the genetic method and its application in the analysis of the depth of temporal facticity, the active self and passive self, we enter into the domain of passive geneses which transport phenomenology to the unconscious dimension. "Thus, our considerations concern a phenomenology of the so-called unconscious." ${ }^{\text {2 }}$ Let us look at this in parts. The world of passivity leads to an obscure, latent, hidden dimension that is veiled from temporal awareness. The point to be stressed is not to sustain Husserl's "nil of vivacity" means the same of Freud's unconscious. Although Husserl referred several times to a recondite and anonymous dimension of self, a deep part of existence that is not immediately accessible, he always did so cautiously, placing the word in brackets, or using hedging devices such as "what was then called the unconscious" so that the reader could distinguish his own specific approach. But the aim here is not to set up a dialogue between Husserl and Freud, nor to clarify the differences between their theories. ${ }^{83}$ The aim is to make explicit the theory of Husserl's passive geneses, how this directly

\footnotetext{
79 (Husserl, 1989, p. 225).

80 (Husserl, 1989, p. 267).

81 (Husserl, 2001a, p. 631; Steinbock, 1995, p. 41).

82 (Husserl, 2001a, p. 201).

83 For Freud and Husserl's dialogue on the unconscious, see Bernet, 2003.
} 
connects with inner time-consciousness theory and with the pre-reflective dimension of self, and how these together may offer an important contribution to existential phenomenological psychology.

The theory of passive geneses may extend the horizons of phenomenology and consequently to existential psychotherapy, as other authors have done it. For example, Heidegger, Sartre and Merleau-Ponty have all considered the covert dimension of human existence. Heidegger mentioned that Dasein is not only ontologically distant from itself, for even at the ontic level it is hidden. ${ }^{84}$ Sartre claims that consciousness affects itself pre-reflectively even in bad faith. ${ }^{85}$ As for Merleau-Ponty, in "Phenomenology of Perception", he connected the aims of psychoanalysis with the phenomenological method, linking them with the notion that "all human acts have a meaning;" ${ }^{86}$ later, he would claim that, although psychoanalysis and phenomenology had not followed parallel paths, they both pointed to the notion of latency. ${ }^{87}$ However, an attentive reading of Husserl's theory of passivity and concepts associated with it suggest that it is closer to a psychological language of phenomenological psychology, and therefore may be linked to existential psychotherapy.

\section{Affective Zero-Consciousness}

The primordial laws of the constitution of geneses, of their associative motivational laws, originate in inner time-consciousness. ${ }^{88}$ As we have seen, all retention is always retention of a lived experience. A primordial impression occurs simultaneously with a transformation in the retentional chain and each retention is relegated further back into the past, implying that each experience included in a retention will gradually lose more of its 'force'.

Continuous retentional modification proceeds up to an essentially necessary limit. That is to say: with this intentional modification there goes hand in hand a gradual diminution of prominence; and precisely this has its limit, at which the formerly prominent subsides into universal substratum - the so-called "unconscious", which, far from being a phenomenological nothing, is itself a limit-mode of consciousness. ${ }^{89}$

\footnotetext{
84 "Proximally the 'who' of Dasein is not only a problem ontologically; even ontically it remains concealed." (Heidegger, 1962, p. 152).

85 (Sartre, 1943, p. 83).

86 (Merleau-Ponty, 1945, p. 184).

87 (Merleau-Ponty, 1982, p. 71).

88 (Husserl, 2001a, p. 633).

89 (Husserl, 2001a, p. 217).
} 
Husserl describes the uninterrupted process of transformation of the retentional chain as a 'clouding over' process, ${ }^{90}$ in which all experiences that are initially a primordial impression gradually lose their clarity, traces and salient features, causing their affective force to diminish. ${ }^{91}$ From the psychological point of view, it is fundamental to grasp not only the connection between lived experiences and time consciousness, but also that the retentions that gradually lose their salience are relegated to the "nil of the vivacity of consciousness," or to a space of "affective zero-consciousness". This passive dimension of consciousness is not a nothing of psychological life; the retentions of inner time-consciousness do not disappear. On the contrary, they form the subsoil, the background of lived experiences, which are permanently present as an experiential atmosphere of subjectivity.

This gradation is also what determines a certain concept of consciousness and degrees of consciousness and the opposition to the unconscious in the appropriate sense. The later designates the nil of this vivacity of consciousness and, as will be shown, is in no way a nothing: A nothing only with the respect to affective force and therefore with respect to those accomplishments that presuppose precisely a positively valued affectivity (above the zero-point).... Every concrete datum of the sphere of the living present is submerged, as we know, in the phenomenal past, succumbs to retentional transformation and thereby necessarily leads into the region of affective nullity into which it is incorporated and in which it is not nothing. Thus we must reckon within the living present in general an affective zero-horizon that is constantly varying with the living present itself. ${ }^{92}$

Inner time-consciousness is the place of constant genesis; the meanings created by the self have a history. For Husserl, temporal awareness is a constant becoming. ${ }^{93}$ Passivity is a subsoil that is being constituted throughout a person's development, a space for the creation of a cluster of personality features, of more-or-less sedimented habits, which are sometimes present in a totally passive and obscure form, but which nevertheless play a role in the being of

90 (Husserl, 2001a, p. 217).

91 (Husserl, 1969, p. 319).

92 (Husserl, 2001a, p. 216).

93 "The theory of consciousness is directly a theory of apperceptions; the stream of consciousness is a stream of constant genesis, it is not a mere series, but a development, a process of becoming" (Husserl, 2001a, p. 628). 
subjectivity. One of the main aims of genetic analysis is to explain the constitution of meanings that were sedimented throughout the different phases of development, which Husserl calls habitus, meanings that are in part not immediately accessible to the self.

If the monad necessarily has the form of the unity of becoming, of a unity of unflagging genesis, then its concrete structure is only made up of "elements" that are themselves unities of becoming, and the like the entire monad, these unities of becoming, have an abstract structure with the respect to their phases. Every phase has its own necessities and not merely compossibilities; in this way, every lived-experience that is being "delimited" for itself demands its "background," a horizon; ... The monad is a living unity that bears within itself an ego as the pole of being affective and being affected, and a unity of wakeful and concealed life, a unity of abilities, of "dispositions;" and what is concealed, "unconscious," is a peculiar modality for the discreteness of the monad, a modality whose necessary sense must be fashioned originally in ways peculiar to it. ${ }^{94}$

In short, genetic phenomenological analysis proceeds from the assumption that the self does not have access to all the perspectives of lived experiences. Some are superimposed on others and some are sometimes more prominent than others, for reasons not immediately apprehended, while others are vague or peripheral, transformed or distorted in the retentional process, or, as we shall see below, by associative processes. The analysis of passive geneses places phenomenology before the deep life of the subjectivity. ${ }^{95}$

Having arrived at this point, it now becomes possible to delineate a preliminary contribution to the question raised above concerning the way the self can collapse, a collapse that may be manifested in multiple ways. In the sphere of existential psychotherapy, Spinelli broaches the concept of worlding as an experiential process in which all subjectivity deals simultaneously with the ontological dimensions of existence and with the ontic strategies of being before the givens of existence. ${ }^{96}$ Worlding also expresses how existence is a continuous process and in constant becoming, existence as it is projected outside itself. However, worlding-as-process necessarily has a structure that fuses into a worldview; that is, the more-or-less rigid sedimentations that are gradually established along the personal development of the self, others and 
the world. This worldview includes the personal beliefs, self-vision, meanings, behaviour, emotions and affectivity that the person has created in the interrelational space and upon which he bases himself when dealing with his existence. This worldview structure is complex but "attempts to maintain a structure that places greater value upon the continuation of being rather than upon the cessation of being." ${ }^{\prime 7}$

This assumption is directly in line with the self-preservation that Husserl speaks of and which was mentioned above. But the connection is closer; the worldview and worlding enunciate a basic characteristic of the experiential self which has already been evoked here and which is present in the flow of temporal consciousness - a streaming and a standing. As we have seen, inner time-consciousness and passive geneses form a theory about the way sedimentations are formed and transform into habits, some more rigid than others, and which are constituted in the experiential self. The first principle of existential psychotherapy is that the self is grounded relatedness. For this reason, uncertainty and existential anguish are two dimensions of human existence which arise from this presupposition, as everything that is developed is lived in the uncertainty of the intersubjective space. Inevitably, there will be tensions and conflicts that arise from one's own existential project, between worlding as process and the sedimentations of the worldview. These conflicts may result in different types of psychological manifestations and disturbances, and, in extreme cases, with the collapse of the self; according to the existential approach, tensions arise that are inherent to the experience of the givens of existence. $^{98}$

\section{Phenomenology of Association, Intentional Motivations and Affective Allure}

In order to acquire a more in-depth understanding of the theory of passive geneses, psychological concepts such as motivation, association and affective allure need to be explored. Husserl was always clear that these concepts had to be understood in a specifically phenomenological way, and that they should not be confused with the meanings they are given in naturalist psychology. ${ }^{99}$ Even before his work into passive syntheses, in Ideas II, in creating a clear distinction between the Naturalist and Personalist Worlds, he introduces the concept of intentional motivation as the essential law of personal self. ${ }^{100}$ In the

\footnotetext{
97 (Spinelli, 2007, p. 32).

98 (Yalom, 1980, p. 8).

99 (Husserl, 2001a, p. 162; Husserl, 2001b, p. 99).

100 (Husserl, 1989, p. 231).
} 
world of subjectivities, of people, this implies intentional motivations, ${ }^{101}$ both intrinsic to each subject and intersubjectively between subjects. From the idiosyncratic perspective, there are motivations that are veiled from self knowledge, and which inclusively interconnect in "associative motivation networks." These include sedimentations of cognitive acts, memories, and also apperceptions, non-thematized pre-reflective acts, sensorial acts, therefore a whole non-rational dimension of self.

By all means, there are hidden motivations. Even without our performing acts of belief, they enter into motivations. Examples of it are provided by the realm of experience, the infinitive field of motivations included in every perception, in memory, and (modified, however) in every phantasizing of a thing. Apprehensions of things and of thingly nexuses are "webs of motivation" ... ${ }^{102}$ Here it is not a matter of a motivation of position-takings by other position-takings (active theses by active theses) but of lived experiences of any sort whatsoever. These are, specifically "sediments" of earlier acts and accomplishments of reason, or ones which emerge, in "analogy" with the former, as apperceptive unities without actually being formed out of acts of reason, or else they are completely a-rational: sensibility, what imposes itself, the pre-given, the driven in the sphere of passivity. ${ }^{103}$

Husserl considered phenomenology of association ${ }^{104}$ to be a continuation of inner-time consciousness theory ${ }^{105}$ as crucial for transcendental phenomenology as for phenomenological psychology, ${ }^{106}$ reaffirming thus how associative processes add one more important detail to the comprehension of motivations of facticity. Not only are associative processes transmitted between and through previously established sedimentations, the associative laws of

101 "All these are phenomenological relations which can be found and described only in the purely intentional sphere" (Husserl, 1989, p. 233).

102 (Husserl, 1989, p. 236).

103 (Husserl, 1989, p. 234).

104 "The rubric 'association' characterizes for us a form and a lawful regularity of immanent genesis that constantly belongs to consciousness in general; but it does not characterize, as it does for psychologists, a form of objective, psychophysical causality" (Husserl, 2001a, p. 162).

105 (Husserl, 2001a, p. 163).

106 (Husserl, 2001b, p. 105). 
intentional motivations occur without any conscientialization of self. ${ }^{107}$ These networks of associative motivations occur in progressive and regressive movements, influencing each other mutually in such a way that past experiences may flow into future expectations or present action, just as pre-reflective expectations (protention actions) may influence sedimentations or acquired habits. ${ }^{108}$

Much phenomenology of association highlights the fact that associative trajectories take place in the sphere of passive geneses; they are not previously defined or reflectively elaborated upon by the self, yet nevertheless retain their influence on it, either by remaining in the passive sphere or by articulating influences between the passive and active self. ${ }^{109}$ Thus, a motivational association may arise in the consciousness through an "affective allure":

By affection we understand the allure given to consciousness, the peculiar pull that an object given to consciousness exercises on the ego; it is a pull that an object given to consciousness exercises on the ego; it is a pull that is relaxed when the ego turns toward it attentively, and progress from here... ${ }^{110}$

Between thought and feelings, cognition and emotion, the self has various experiences that simultaneously exert an allure upon it. Affection presupposes a prominence, a contrast, for either cognitive or affective reasons. A lived experience produces an affection in the self, which for its part will imply a 'relief' of that same allure when the self reacts to it. However (and this is a particularly important point from the psychological perspective), even when the self does

107 "But associations can also run their course without being noticed. Just as we fail to notice so many different things that are in our field of consciousness, so too, we fail to notice the connections of association" (Husserl, 2001a, p. 163).

108 "They are built through and through from intentional rays, which with their sensecontent and their filled content, refer back and forth, and they let themselves be explicated in that the accomplishing subject can enter into these nexus.... every thing here is 'motivated,' including every new positing and every phase of the unitary total positing as well as every new partial positing which may perhaps come to foreground but does not have to." (Husserl, 1989, p. 236).

109 "Already mere receptivity, namely, again every 'I notice, I grasp, I consider' which starts from the I center, presupposes that what is to be grasped already previously lay ungrasped in the field of consciousness of the grasping I and exercises an affection, an attraction upon the I, to turn attentively toward it. Thus as we see, prior to the noticing experience there is already an unnoticing experience (...)." (Husserl, 1977, p. 100).

110 (Husserl, 2001a, p. 196). 
not direct all its attention, even when the self is not totally active in relation to that experience, the affection may even diminish in force. As Husserl said, there is relief in the sense that the attraction provoked a genuine effect in the self, even when "it remains in the antechamber of the self."111

\section{Associative Reactivation and Passive Geneses}

Finally, three aspects need to be mentioned that are crucial for existential psychotherapy. Firstly, passive geneses may be reactivated even when they have lost affective force and are in zero consciousness. Secondly, the importance of passive geneses does not have to do only with retentions (that is to say, with experiences of the past); equally important is research into protentions (i.e. passive expectations). Thirdly, all experiences lived in a particularly stream of consciousness, in a particular self, influence each other mutually. This is one of the reasons why phenomenology of association gives particular importance to the phenomenological investigation of memory. ${ }^{112}$ Phenomenology of association also connects the first point mentioned (i.e. that associative processes can provoke reactivations of experiences, even those that are occult). Husserl uses the term 'awakening', defined as follows:

By awakening we understand and distinguish two things: awakening something that is already given to consciousness as for itself, and the awakening of something that is concealed.

As we have seen, in first place, the primordial impressions that become retentions gradually lose prominence and are sedimented in zero consciousness. However, what is sedimented is the original meaning of the lived experience. Thus, an experience may be inactive in the consciousness but its meaning is implicit and is kept present, though in an occult form. Experiences of the lived present may reactivate retentions and passive geneses through an 'associative awakening. 113 There are many reasons why a particular retention may be reactivated, and these may be both cognitive and rational, and emotive and

\footnotetext{
111 (Husserl, 2001a, p. 215).

112 "Right in the midst of these facts are the phenomena that interest us: the splitting of rememberings into rememberings. These rememberings have been muddled." (Husserl, 2001a, p. 164).

113 "Thus, an associative awakening proceeds from the present toward a retentional past that had already arisen originally prior to this association and is fading away." (Husserl, 20o1a, p. 120).
} 
pre-reflective. ${ }^{114}$ What is more, the associative process does not follow previously defined routes; the reactivations may 'touch upon' different sedimentations that were not initially interconnected. ${ }^{115}$ Associative recollections, which include the retentions upon which they are based, should be distinguished from traditional memory. ${ }^{116}$ This question emphasizes the existence of an extensive horizon in the experience of self, which, passively, continues to permit the elaboration of associations between past experiences, or future expectations, on an implicit pre-reflective level. This hidden experiential sea, for its part, may be reactivated, though it is not possible to anticipate how that will happen or the form that it will take in particular situations that occur.

Certainly, there is an unmistakable distinction between the awakening of the entirely submerged sphere, the distant sphere, and the awakening of empty intentions (or of their contents) that are still in wakeful life or that are standing on the edge of life.... But first: awakening is possible because the constituted sense is actually implied in backgroundconsciousness, in the non-living form that is called here unconsciousness.

We should also remember that everything that has been said about retention (and in fact Husserl gives particular importance to the exploration of memory networks), the laws of passive genesis and associative reactivation processes also apply to protentions. Indeed, protention is presented as having priority for the updating of present experience, and is the temporal foundation of intentionality. ${ }^{17}$ It is obviously important for the psychotherapeutic process, for as we know, the existential approach always emphasised the future dimension of lived experience and how this connects with and influences present experiences.

\section{The Person}

We have already plumbed the depths of the passive geneses of self. Now it is time to move upwards in the direction of Husserl's notion of the person. Inner time-consciousness, the experiential self and passive geneses form a theoreti-

\footnotetext{
114 (Husserl, 2001a, p. 227).

115 "But it is clear that awakening is not tied continuously or in leaps into the other layers of sedimentation. (... ) The awakening can jump from one sedimented layer to another, which can be now higher, now deeper; it can jump in leaps and without any determinate order." (Husserl, 2001a, p. 233).

116 (Drummond, 2003, p. 78).

117 (Roemeyer, 2003, p. 139).
} 
cal triad that is fundamental for psychological and psychotherapeutic praxis. However, it would be incomplete if we did not consider the notion of the person, the relationship between the person and the other, and how the former is constituted intersubjectively. According to Husserl, intersubjectivity conditions must be fulfilled for a person to develop beyond basic selfhood. ${ }^{118}$

As a person, I am what I am (and each person is what he is) as subject of a surrounding world. The concepts of Ego and surrounding world are related to another inseparably.... The surrounding world is the world that is perceived by the person in his acts, his remembered, grasped in thought, surmised or revealed as such and such; it is the world which is there for it to which it relates in this or that way, e.g. by way of thematically experiencing and theorizing as regards the appearing things or by the way of feeling, evaluating, acting, shaping technically, etc.... And a person is precisely a person who represents, feels, evaluates, strives, and acts and who, in every such personal act, stands in relation to something, to objects in his surrounding world. ${ }^{119}$

Basic ipseity implies growth and development in order to achieve the plenitude of a personal identity. The concept of person is phenomenologically and ontologically dependent on the experiential self, ${ }^{120}$ but basic selfhood, while being a necessary condition, is not in itself enough to constitute a personal identity; it has to be developed within a social and cultural context, with the Other. ${ }^{121}$

Genetic phenomenological analysis involves describing and interpreting meanings that have become sedimented during the course of personal development, at its different phases, during its interaction with the family and with social and cultural environments. It also involves describing and making explicit expectations that are present in the associative networks of protention. ${ }^{122}$ In a surrounding world, the experiential self is situated as a basic ipseity that includes sensations, associations, passive geneses, and stimuli,

118 (Husserl, 1989, p. 118).

119 (Husserl, 1989, p. 195).

120 (Zahavi, 2005, p. 129).

121 (Zahavi, 1999, p. 160).

122 "I come across theses bases also when I want to understand someone's development. I have then to describe, going from stage to stage, the surrounding world in which he grew up and how he was motivated by the things and people of his environment just as they appeared to him and as he saw them. Here we touch upon facticity, in itself beyond our comprehension" (Husserl, 1989, p. 288). 
which remain largely hidden, though they passively influence the activity of the active self, of the person. They influence its being-in-the-world, its thought, affectivity, behaviour. The experiential self is the container of the obscure moods of the person. ${ }^{123}$ At the level of personal development, we not only consider a stream of abstract consciousness, or experiences flowing in the retentional chain, ${ }^{124}$ but also the sedimented dispositions, traces of personality, affectivity, the meaning inherent in passive and active geneses and their idiosyncratic components as expressed through thought, the body, affectivity and the person's behaviour. Genetic phenomenological analysis has as its object of study the person, who has a history and a unique life. From the psychological and psychotherapeutic point of view, it considers the connection between the experiential self and the person, knowing that it is in the presence of a unique subjectivity. The person is the object of exploration, containing within himself an experiential self, the core of the lived experience.

There exists a continuous two-way flow between the experiential self and the surrounding world, i.e. a bidirectional influence that is dynamic and constant between the dimension of the self, the person and the intersubjective space of the surrounding world. The interconnection, hiatus, contrasts, oppositions, cracks between these two worlds that are both an integral part of the existential project result, or may result, in conflict or in the loss of adequate self-preservation. A dramatic change in one of these dimensions, in the self or in the world, will necessarily influence the other. ${ }^{125}$ However, psychological disturbance, and in extreme cases, the loss of meaning, occur in the intersubjective space and are the result of disruptive interrelational processes.

The sedimentations which are at zero consciousness may spontaneously unleash a reactivation in the self as a consequence of a confrontation between aspects sedimented in the experiential self and the experiences of the surrounding world. As mentioned above, in the process of personal development, there will certainly be a place for the confrontation between the structural dimension of self based on sedimentations and the process of becoming, which is the characteristic dimension of being in the world. There is a continu-

123 "The specifically spiritual Ego, the subject of spiritual acts, the person finds itself dependent on an obscure underlying basis of traits of character, original and latent dispositions, and thereby dependent on nature" (Husserl, 1989, p. 288).

124 "The nexus of lived experiences of a person is not a mere bundle of lived experiences or a mere 'stream' of consciousness in which the lived experiences flow away. Instead, every lived experience is a lived experience of an Ego, of an Ego that does not itself flow away in a stream as its lived experiences do." (Husserl, 1989, p. 29o).

125 (Stolorow, 2009, p. 407). 
ous two-way flux between the 'inner' world of the self and the 'outer' world of the surrounding environment. A dramatic change in one of the systems influences the other. This existential tension is what I call paradoxical reversibility. Change is an intrinsic part of the human condition. The matter has to do with cognitive and emotional abilities and resilience that each person has, from one moment to the next, to deal with the affective forces of the self, together with the challenges that are raised in the interrelational space. Sartre mentions the restlessness that characterises the fatality of consciousness becoming spontaneously anguished. ${ }^{126}$ Suddenly, sometimes for no apparent reason, the consciousness will become anguished; it is as if that anguish were a possibility that is always there. At these moments, the introduction of phenomenological reduction is not a learned or intellectual operation, but rather a way of achieving a true and authentic connection as the mode of being. The existential conflict may arise from an impact that is produced in the self as a result of its interactions with the surrounding world, and which may unleash dissociative processes. ${ }^{127}$ The dissociation may involve the different strategies that the self develops in response to the challenge raised to one of the sedimented dimensions: for example, the suppression, negation or redirecting of existential tension, which can be translated into false beliefs or behaviours that are not in tune with an authentic way of being. In extreme situations, the conflict may lead to the fragmentation of self, the loss or annihilation of the sense of being a person. ${ }^{128}$ The concept of reactivation mentioned by Husserl may be understood in two ways from the psychological and psychotherapeutic point of view. On the one hand, the reactivations of associative networks intertwine sedimented meanings which, when confronted with the thematic horizon of mundane experiences, may unleash existential anguish. On the other, that which is defined here as reflexive reactivation is a psychotherapeutic objective, in the sense that it seeks to phenomenologically investigate the constitution of meaning in passive geneses, which in turn may only happen in the sphere of a privileged interrelationship space.

\section{Conclusion}

While the static phenomenology is wide known in psychology, the genetic method is still not considered in the field. Phenomenological psychologists

\footnotetext{
126 (Sartre, 1994a, p. 81).

127 (Spinelli, 2007, p. 37).

128 (Orange, Atwood, Stolorow, 2001, p. 48).
} 
tend to identify their work either based on the Hussserlian descriptive approach or on the hermeneutic work defended by others phenomenologists. This paper aimed to present a new framework to phenomenological psychology based on Husserl's static and genetic methods that are not to be understood as two separated methodologies, although, their goals are different. The present text, besides presenting the new framework, has focused above all on the theoretical underpinnings of genetic phenomenology, which require subsequent adaptation and integration into the praxis of phenomenological psychology and existential psychotherapy. However, we identified a triad that sustains the genetic theory as proposed: inner time-consciousness, the experiential self and the theory of passive genesis. Future work will seek to show how the relationship between static and genetic methods may have a specific application to the field of research. In the specific case of genetic phenomenology, other concepts must be developed and presented and, in particular, must be submitted clinical cases with a reading based on genetic analysis.

\section{References}

Bernet, R. (2003). Unconscious Consciousness in Husserl and Freud. In The New Husserl.

A Critical Reader. Donn Welton (Ed.). Bloomington: Indiana University Press.

Bernet, R. (2003b). Gaze, Drive and Body in Lacan and Merleau-Ponty. In Psychosis:

Phenomenological and Psychoanalytical Approaches. Josef Corveleyn and Paul Moyaert (Eds.). Leuven: Leuven University Press.

Bernet, R., Kern, I. \& Marbach, E. (1993). An Introduction to Husserlian Phenomenology. Evanston: Northwestern University Press.

Damásio, A. (1999). O Sentimento de Si. Lisboa: Publicações Europa-América.

Depraz, N. (2001). Husserlian Theory of Intersubjectivity as Alterity. In Between Ourselves. Evan Thompson (Ed.). Thorverton: Imprint Academic.

Drummond. J. L. (2003). The Structure of Intentionality. In The New Husserl. A Critical Reader. Donn Welton (Ed.). Bloomington: Indiana University Press.

Gallagher, S. (2007). Pathologies in Narrative Structures. In Narrative and Understanding Persons. Daniel D. Hutto (Ed.). Cambridge: Cambridge University Press.

Gallagher, S. \& Zahavi D. (2005). Phenomenological approaches to self-awareness. The Stanford Encyclopedia of Philosophy. Edward N. Zalta (ed.). Stanford: Stanford University.

Greenberg, L. S. \& Paivio, S. C. (1997). Working with Emotions in Psychotherapy. New York: The Guilford Press.

Heidegger, M. (1988). The Basic Problems of Phenomenology. Indianapolis: Indiana University Press. 
Heidegger, M. (1962). Being and Time. Oxford: Basil Blackwell.

Heidegger, M. (1998). Carta Sobre o Humanismo. Lisboa: Guimarães Editores.

Held, K. (2003). Husserl's Phenomenology of the Life-World. In The New Husserl.

A Critical Reader. Donn Welton (Ed.). Bloomington: Indiana University Press.

Husserl, E. (2006). The Basic Problems of Phenomenology. Dordrecht: Springer.

Husserl, E. (2001a). Analyses Concerning Passive and Active Synthesis. Lectures on Transcendental Logic. Dordrecht: Kluwer Academic Publishers.

Husserl, E. (2001b). Meditações Cartesianas. Porto: Rés.

Husserl, E. (2001c). Logical Investigations. Oxon: Routledge.

Husserl, E. (1994). Lições para uma fenomenologia da consciência interna do tempo. Lisboa: Imprensa Nacional - Casa da Moeda.

Husserl, E. (1989). Ideas pertaining to a pure phenomenology and to a phenomenological philosophy: second book. Dordrecht: Kluwer.

Husserl, E. (1983). Ideas pertaining to a pure phenomenology and to a phenomenological philosophy: first book. Dordrecht: Kluwer.

Husserl, E. (1977). Phenomenological Psychology. The Hague: Martinus Nijhoff.

Husserl, E. (1968). Formal and Transcendental Logic. The Hague: Martinus Nijhoff.

May, R., Angel, E., \& Ellenberger, F. H. (2004). Existence. New York: Aronson.

Merleau-Ponty, M. (1982). Phenomenology and Psychoanalysis. Preface to Hesnard's L'Oeuvre de Freud. In Merleau-Ponty \& Psychology. Keith Hoeller (Ed.). New Jersey: Humanities Press.

Merleau-Ponty, M. (1964). Le visible et l'invisible. Paris: Gallimard.

Merleau-Ponty, M. (2002). Phenomenology of Perception. London: Routledge \& Kegan Paul.

Mohanty, J. N. (2008). The Philosophy of Edmund Husserl. New Haven: Yale University Press.

Montavont, A. (1999). De la passivité dans la phenomenology de Husserl. Paris: Presses Universitaires de France.

Orange, D., Atwood, G., Stolorow, R. (2001). Working Intersubjectively. Contextualism in Psychoanalysis Practice. Hove: Psychology Press.

Parnas, J. (2003). Self and schizophrenia: a phenomenological perspective. In The Self in Neuroscience and Psychiatry. Tilo Kircher \& Anthony David (Ed.). Cambridge: Cambridge University Press.

Rodemeyer, L. (2003). Developments on the Theory of Time-Consciousness. An Analysis of Protention. In The New Husserl. A Critical Reader. Donn Welton(Ed.). Bloomington: Indiana University Press.

Sartre, J. P. (1943). Lêtre et le néant. Paris: Gallimard. Translated into English as Being and Nothingness (1969/1953), Abingdon: Routledge.

Sartre, J. P. (1940). L'imaginaire. Paris: Gallimard.

Sartre, J. P. (1994a). A Transcedência do Ego. Lisboa: Edições Colibri. 
Sartre, J. P. (1994b) A Consciência de si e Conhecimento de si. Lisboa: Edições Colibri.

Sass, L. A. (2003). Self-disturbance in schizophrenia: hyperreflexivity and disminished self-affection. In The Self in Neuroscience and Psychiatry. Tilo Kircher \& Anthony David (Ed.). Cambridge: Cambridge University Press.

Spinelli, E. (2007). Practising Existential Psychotherapy. The Relational World. London: Sage.

Spinelli, E. (2001). The Mirror and the Hammer. Challenging Orthodoxies in Psychotherapeutic Thought. New York: Continuum.

Spinelli, E. (1997). Tales of Un-Knowing. Eight Stories of Existential Therapy. New York: New York University Press.

Steinbock, A. J. (1995). Home and Beyond. Generative Phenomenology After Husserl. Evanston: Northwestern University Press.

Stolorow, R. (2009). Individuality in Context. International Journal of Psychoanalytic Self Psychology. 4: 405-413.

Stolorow, R. (2007). Trauma and Human Existence. New York: The Analytic Press.

Stolorow, R., Atwood, G. (1992). Contexts of Being. The Intersubjective Foundations of Psychological Life. New York: The Analytic Press.

Zahavi, D. (2007). Self and Other: The limits of narrative understanding. In Narrative and Understanding Persons. Daniel D. Hutto (Ed.). Cambridge: Cambridge University Press.

Zahavi, D. (2005). Subjectivity and Selfhood. Investigating the First-Person Perspective. Cambridge: The MIT Press.

Zahavi, D. (2004). Alterity in Self. In Ipseity and Alterity. Interdisciplinary Approaches to Intersubjectivity. S. Gallagher, S. Watson, Ph. Brun \& Ph. Romanski (eds.). Rouen: Presses Universitaires de Rouen.

Zahavi, D. (2003a). Inner Time-Consciousness and Pre-reflective Self-Awareness. In The New Husserl. A Critical Reader. D. Welton (Ed.). Bloomington: Indiana University Press.

Zahavi, D. (2003b). Phenomenology of Self. In The Self in Neuroscience and Psychiatry. Tilo Kircher \& Anthony David (Ed.). Cambridge: Cambridge University Press.

Zahavi, D. (200o). Self and Consciousness. In Exploring the Self. Advances in Counsciouness Research. Dan Zahavi (Ed.). Amsterdam: John Benjamins Publishing Company.

Zahavi, D. (1999). Self-Awareness and Alterity. A Phenomenological Investigation. Evanston: Northwestern University Press.

Zahavi, D. (1998). Self-Awareness and Affection. In Alterity and Facticity. N. Depraz \& Dan Zahavi (Eds.). Dordrecht: Kluwer Academic Publishers. 
Copyright of Journal of Phenomenological Psychology is the property of Brill Academic Publishers and its content may not be copied or emailed to multiple sites or posted to a listserv without the copyright holder's express written permission. However, users may print, download, or email articles for individual use. 